\title{
Problems Faced by Teachers During the Pandemic for Teaching: An Exploratory Study
}

\author{
Sheema Kumari ${ }^{1}$ and Rasmirekha Sethy ${ }^{2 *}$ \\ ${ }^{1}$ Research Scholar, Regional Institute of Education, Bhubaneswar, Odisha, India \\ ${ }^{2}$ Associate Professor, Regional Institute of Education, Bhubaneswar, Odisha, India \\ *Corresponding author: drrasmirekhasethy@gmail.com
}

Received: 11-09-2021 Revised: 25-11-2021 Accepted: 15-12-2021

\begin{abstract}
The surge of COVID-19 pandemic has put education sector to a new phase of online mode of teaching and learning. The sudden shift from traditional mode of teaching and learning has put forth both problems and challenges in front of all stakeholders. In this crucial situation, the present study aimed to examine the perception and problems faced by the secondary school teachers of Ranchi district of Jharkhand state, India. Survey method was adopted to carry out the study and self-developed questionnaire wasused to capture data. Secondary school teachers of Ranchi district were considered as population and 28 teachers from five secondary schools of Ranchi district were selected as sample randomly. The study found that $79 \%$ teachers opted for offline classes over online classes, 36\% teachers found their home environment not much suitable, $39 \%$ found that not much interaction could happen during online classes, $54 \%$ teachers were spending 1-3 hours in online classes, $50 \%$ teachers felt that sometimes it takes great effort for teachers to explain simple concepts/chapters in the online class, $50 \%$ teachers were feeling that sometimes it is difficult to complete the syllabus due to online studies, $47 \%$ teachers found online teaching during pandemic is slightly stressful, 39\% teachers found it little difficult sometimes to connect with individual students through online teaching, 75\% teachers felt that they faced difficulties in delivering lesson in online class and 32\% teachers always felt uneasy due to too much use of mobile phone/laptop/ tablet. It concludes with highlighting the support from government, parents, institutions, teachers and educationists required to make online learning more accessible and effective.
\end{abstract}

Keywords: Covid-19, Online class, Offline class, Digital device, Mobile applications

The impact of COVID-19 on the education sector cannot be ignored as it will have a long-term impact on India's growth, development, economic, societal consequences, etc. As we know, due to a Coronavirus pandemic, state governments across the country have temporarily shut down schools to avoid the spread of coronavirus due to which teachers and students have faced major challenges to continue their education. There is transition from in-person classes to online instruction occurs in a groundbreaking and staggering way, which constitutes a significant challenge for teachers. They have been adapting their lessons to virtual environments to continue their labor of educating learners. To do such a thing, educators have encountered and interacted with numerous online resources presently available (e.g., learning management systems, video conferences apps, blogs, online games, and collaborative spaces etc.).On the other hand, "students taking online classes could face difficulties that they might never have encountered in a traditional teaching and learning environment". For instance, they are expected to access information and interact with peers and teachers through technological devices and applications to sign appropriate participation.

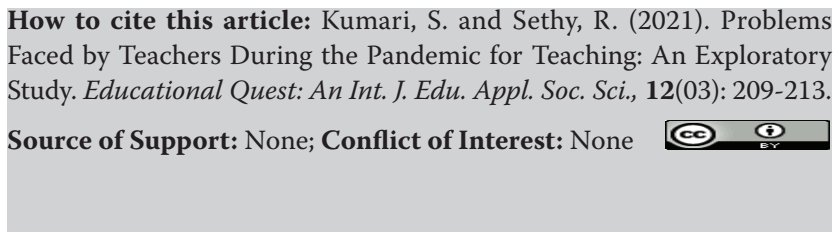
Faced by Teachers During the Pandemic for Teaching: An Exploratory Study. Educational Quest: An Int. J. Edu. Appl. Soc. Sci., 12(03): 209-213. Source of Support: None; Conflict of Interest: None (c) 9 
However, it should be considered that not every student and teachers are trained/skilled to adopt new technologies. Some respond with enthusiasm and a desire to become the master of the machines; others approach the situation with fear and apprehension. In other words, not following a lesson could cause anxiety, demotivation, and some extra elements that teachers would have to deal with. It is a fact that this outbreak has forced teachers of all subjects to change their teaching procedures.

\section{Rationale of the Study}

Online teaching was the only option for educators and teachers to continue education at all levels of formal education during the lockdown. Government of India as well as states have tried at their best to orient teachers and learners in the basics of online teaching and assessment. In spite of all the efforts, teachers and students faced problems and challenges which were explored by researchers in different fields. Albert and Solomon et al. (2020) revealed that the factors that militate against students' compliance with e-learning during theCOVID-19 lockdown include poor budgetary allocations to the education sector, illiteracy of many parents, erratic/epileptic power supply, poor infrastructures in the schools, poor parents and did not have computers /laptops in their homes, many teachers were not ICT compliant. Deepti and Ayush (2020) found that most people faced internet problems and did not have the knowledge to use and solve problems related to technology. Lack of human interaction between teachers and students as well as among the students, lack of physical spaces at home and support of parents were some of the challenges faced by teachers during teaching learning process in the lockdown period (Fernando and Patrizia et al. 2020). Juliana et al. (2020) identified lack of mastery in technology, additional internet quota costs, additional work for parents in assisting children in learning, communication and socialization between students, teachers and parents were reduced and elongated working hours were some of the problems faced by the teachers, students and parents. Sangeeta and Tandon (2020) revealed effort expectancy failed to drive teachers' adoption of online teaching. Bharati and Sthitaprajan (2016) found that in English writing the students faced problems in relation to content, organization of ideas, and language in use and suggested the adoption of process-oriented approach to be an effective strategy for maintaining a positive, encouraging and collaborative learning. Kachhap and Namta (2015) also revealed that lack of infrastructure, improper guideline at the government level, no appointment of teachers on regular basis were some of the major hurdles faced by teachers. Lack of support from government agencies, increase in misconduct of students, classroom control and lack of physical infrastructure were the major problems faced by the teachers in teaching (Chaudhry, 2014).

The above studies were able to address different problems faced by the school teachers in various contexts in both offline and online mode of teaching and learning process. The sudden transformation of mode of teaching and learning might have different demands and challenges. Education should spell out the kinds of desirable changes needed by the society and now these changes are to be brought among the students. For this, educational research should try to study and understand various problems of the society in specific areas from time to time and should become an integral part of social development. For this, the researcher finds an area to explore the problems faced by the teachers at secondary level through the online mode of teaching and learning during the Pandemic period in Ranchi district of Jharkhand. Accordingly the study is entitled as 'problems faced by secondary school teachers during Pandemic in Ranchi district'.

\section{Objectives}

1. To study the perception of secondary school teachers about online mode of teaching and learning.

2. To study theproblems faced by secondary school teachers for taking online classes during the Pandemic.

\section{Methodology}

Survey method was adopted to collect data for the present study looking at the Covid-19 Pandemic situation.The population of the study was all secondary school teachers of Ranchi district.Simple random sampling technique was used for selecting sample. 28 teachers were selected from five different secondary schools of Ranchi district (14 male and 14 
female teachers), both government (80\%) and private $(20 \%)$ schools like Jawahar Navodaya Vidyalaya Mesra, Sohowati Devi Public School, Childag, Aadarsh High School Rugri, Rajkiya Pichdi Jati Aavasiy Balika, Vidyalaya Lalpur, TVS High School Jagarnathpur of Ranchi district. Self-developed questionnaire was used for data collection. The questionnaire was having total seventeen questions capturing the perception of secondary school teachers and the difficulties faced by them during taking classes through online mode. The items cover two aspects such as perception of teachers towards online teaching and problems faced by the teacher during the online teaching. The items were based on suitability of home environment, interaction in online class, syllabus completion, clearance of doubts, impact on teachers, difficulty in lesson delivery etc. Data were analyzed and presented in form of percentage and accordingly interpretation was made.

\section{ANALYSIS AND INTERPRETATION}

To analyze the survey data, statistical methods were employed to determine the problems faced by secondary school teachers during Pandemic in Ranchi District. The study is concerned almost exclusively with the sensitization of problems faced by teachers and student due to sudden shift of classroom (offline classes) to online classes (elearning) due to Pandemic

\section{Perception of Teachers towards Online Teaching}

$79 \%$ of teachers opted for offline classes over online classes (21\%). 39\% teachers were finding teaching without backboard is not much difficult task, whereas $18 \%$ teachers were acquainted with online teaching and agreed that they had alternatives for using blackboard.

$21 \%$ teachers found their home environment a lot suitable for online classes, $25 \%$ felt little suitable for some time whereas $36 \%$ teachers found their home environment not much suitable and $18 \%$ teachers found their home environment not at all suitable for online classes.

$29 \%$ teachers felt that the student teacher interaction was interesting whereas 39\% found that not so much interaction could happen during online classes and 32\% found average interaction was there during online classes.

54\% teachers were spending 1-3 hours in online classes, $32 \%$ teachers were spending 3-5 hours where as $10 \%$ were reported to spend more than 7 hours in online classes on daily basis.

$50 \%$ teachers felt that sometimes it takes great effort for teachers to explaining simple concepts/chapters in the online class whereas $18 \%$ teachers were finding to put a lot of great effort for teachers to explaining simple concepts/ chapters in the online classes but $21 \%$ teachers felt not much effort was required.

$50 \%$ teachers were feeling that sometimes it is difficult to complete the syllabus due to online studies whereas $18 \%$ teachers were not feeling difficult to complete the syllabus due to online studies.

$43 \%$ teachers like new technologies which may require new approaches to learning and problem solving whereas $36 \%$ teachers took a little interest and 18\% teachers took not much interest in learning new technologies.

$\square$ 61\% teachers felt their expectations as different from traditional schools in the term of time and work whereas $25 \%$ felt slightly different and $14 \%$ could not define their expectations.

$47 \%$ teachers found online teaching during pandemic is slightly stressful, $21 \%$ teachers felt moderate stressful whereas $25 \%$ didn't feel stressful at all but $7 \%$ teachers felt it extremely stressful.

$25 \%$ teachers were agreeing that lots of doubts can be cleared through online classes whereas $72 \%$ teachers were finding very little difficult to clear doubts of students during online classes.

\section{Problems Faced by Secondary School Teachers in Online Teaching}

$39 \%$ teachers found it little difficult sometimes to connect with individual students through online teaching, 36\% teachers found it a lot of difficult to connect, $14 \%$ of teachers did not find much difficulty and 11\% teachers did not find it difficult at all to connect with individual students.

$50 \%$ teachers felt comfortable to take online 
classes in the home environment whereas 25\% teachers felt too much difficult to take online classes in home environment.

$25 \%$ teachers were agreeing that not much difficulties were faced in delivering lectures through digital mediums whereas $75 \%$ teachers felt that they faced difficulties in delivering lesson in online class.

$21 \%$ teachers were not feeling uneasy due to excessive use of digital devices, $47 \%$ felt sometimes whereas $32 \%$ teachers always felt uneasy due to too much use of mobile phone/ laptop/ tablet.

$57 \%$ teachers were facing little difficulties while taking online classes whereas $22 \%$ teachers were facing a lot of difficulties and $21 \%$ teachers were not facing difficulties at all.

$61 \%$ teachers were facing little issue sometimes in delivering education through the digital medium, 19\% teachers were not facing much difficulty whereas $20 \%$ teachers said they faced a lot of issues in delivering education through digital medium.

\section{MAJOR FINDINGS}

$79 \%$ of teachers opted for offline classes over online classes (21\%). 21\% teachers found their home environment a lot suitable for online classes and 36\% teachers found their home environment not much suitable.

$29 \%$ teachers felt that the student teacher interaction was interesting whereas 39\% found that not so much interaction could happen during online classes. $54 \%$ teachers were spending 1-3 hours in online classes.

$50 \%$ teachers felt that sometimes it takes great effort for teachers to explaining simple concepts/ chapters in the online class. $50 \%$ teachers were feeling that sometimes it is difficult to complete the syllabus due to online studies.

$47 \%$ teachers found online teaching during pandemic is slightly stressful. $72 \%$ teachers were finding very little difficult to clear doubts of students during online classes.

$39 \%$ teachers found it little difficult sometimes to connect with individual students through online teaching. $50 \%$ teachers felt comfortable to take online classes in the home environment.
$75 \%$ teachers felt that they faced difficulties in delivering lesson in online class.32\% teachers always felt uneasy due to too much use of mobile phone/laptop/ tablet.

$61 \%$ teachers were facing little issue sometimes in delivering education through the digital medium

\section{EDUCATIONAL IMPLICATIONS}

The findings of this research provide significant implications to the policy makers of the schools to encourage online teaching at the time of Pandemic outbreak.

The administrators of schools should improve performance expectancy as it had significant relationship with behavioral intention and attitude to conduct online classes.

$\checkmark$ For performance expectancy, teachers need to be trained about the benefits and usefulness of online teaching. Further, those teachers who do not understand the usefulness of the technology were unable to adopt the technology.

$\square$ Those teachers who are conducting classes online could convince their colleagues to adopt online teaching. A positive incentive could also be linked with those teachers who are promoting as well as motivating their colleagues to adopt online teaching. These teachers can also discuss their experience with those teachers who are reluctant to adopt the technology.

$\square$ Teachers should set clear expectations and most important is, they should ensure enough time to dedicate to their course and can consistently attend all aspects of the programme, including any live teaching sessions.

$\square$ Teachers should take care about the timing of class. The teaching period should not be longer than 1 hour. Excessive of long classes may reduce children's interest from study, and get irritated from study.

Teachers should check all the technical requirements before committing to start an online course, including any specific software or hardware equipment that they may need.

Study space/area should be conducive for learning. Ensure that teachers have both 
sufficient lighting to avoid eye strain and a comfortable chair and desk to avoid any discomfort.

Another most important is to get organized. Organization is the key to successful online learning. Creating a study plan will help to meet deadlines and work around teachers existing commitments and responsibilities.

\section{CONCLUSION}

The sudden shift from traditional classroom to online classroom put challenges as well as brought newness to the education system. Though developing country like India was not ready enough to equip this change, but the teachers as well as students adopted as far as possible. The situation taught us to move forward with the challenges and difficulties. At the beginning, adopting online mode of teaching was not possible for many teachers as well as students but gradually acceptance to online mode caught a high speed throughout the country. In this context, in Ranchi district of Jharkhand state a mixed response from secondary school teachers regarding their perceptions and difficulties faced in online classroom was captured. Certain problems like internet connectivity, unsuitable home environment, lack of student teacher interaction was some of the major difficulties were recorded by teachers whereas teachers' willingness to adopt new technology, passionate in taking online classes and completing prescribed syllabus with clearing doubts is admirable. Under this circumstance, its' a call for educationists, government and society to support online mode of teaching and learning to achieve its fullest potential.

\section{REFERENCES}

Albert, Solomon and Felix, 2020. COVID-19 and E-learning in secondary schools in Nigeria, JEAPP, 1.

Bharati and Sthitaprajan. 2016. Writing problems faced by the secondary level students: A study of the Kendrapada district, International Journal of English Language, Literature And Translation Studies, 3(1): 2395-2628.

Choudhry, 2014. A study of teaching related problems experienced by secondary school teachers of Kheda district. International Journal for Research in Education, 3(7).

Deepti and Ayush, 2020. Problems Faced by Students and Teachers During Online Education Due to COVID-19 and How to Resolve Them. $20206^{\text {th }}$ International Conference on Education and Technology (ICET).

Fernando, Patrizia and Tiziana, 2020. Online learning and emergency remote teaching: Opportunities and challenges in emergency situations, Institute for Research on Population and Social Policies, taly; www.mdpi.com/journal/societies

Kachhap and Namta, 2015. A study on problem faced by the teachers at secondary level teacher training programme in Jharkhand, International Journal of Humanities $\mathcal{E}$ Social Science Studies, 1(05): 1-5.

Sangeeta and Tandon, 2020. Factors influencing adoption of online teaching by schoolteachers: A study during COVID-19 pandemic, J. Public Affairs. 2020, www. wileyonlinelibrary.com

Suryaman, Cahyono, Muliansyah, Bustani, Suryani, Fahlevi, Pramono, Purwanto, Purba, Munthe, Juliana, and Harimurti, 2020. Study on COVID-19 pandemic and home online learning system: does it affect the quality of pharmacy School learning? A Multifaceted Review Journal in The Field of Pharmacy, 11(8): 524-530. 
